\title{
Autoantibody Reactive with Three Classes of RNA Polymerases in Sera from Patients with Systemic Sclerosis
}

\author{
Masataka Kuwana, Junichi Kaburaki, Tsuneyo Mimori, Takeshi Tojo, and Mitsuo Homma \\ Division of Rheumatology, Department of Internal Medicine, Keio University School of Medicine, Tokyo 160, Japan
}

\begin{abstract}
We have identified a novel autoantibody reactive with all three classes of RNA polymerases, well-characterized nuclear enzymes, in sera from patients with systemic sclerosis (SSc). After incubation with $\left[{ }^{35} \mathrm{~S}\right]$ methionine-labeled HeLa cell extracts, 14 of 275 SSc sera immunoprecipitated 12 or 14 proteins with similar molecular weights as those of several subunit proteins of eukaryotic RNA polymerases I, II, and III. Purified IgG from these two types of sera inhibited RNA transcription catalyzed by RNA polymerases I, II, and III in vitro. Immunoblot analysis using RNA polymerase-enriched fraction showed that the majority of these sera reacted with $42-$ or $25-\mathrm{kD}$ protein. Anti-RNA polymerase antibody was highly specific to SSc, especially to diffuse cutaneous SSc. Clinical features associated with this antibody included a high frequency of heart and kidney involvement and a poor survival rate at $5 \mathrm{yr}$ after first visit. These findings indicate that the autoantibody to three classes of RNA polymerases is a new marker for a unique subset of diffuse cutaneous SSc. (J. Clin. Invest. 1993. 91:13991404.) Key words: immunoprecipitation $\bullet$ in vitro transcription assay • subunit • autoimmunity • nuclear enzyme
\end{abstract}

\section{Introduction}

Systemic sclerosis (SSc) ${ }^{1}$ is an autoimmune disease characterized by a high frequency of circulating autoantibodies to a variety of cellular components $(1,2)$. Major autoantibodies in SSc sera include antibodies against centromere and DNA topoisomerase I ( topo I). Anticentromere antibody is mainly detected in patients with limited cutaneous SSc and a low frequency of serious internal organ involvement, whereas anti-topo I antibody identifies a subset of more extensive skin involvement and pulmonary interstitial fibrosis (1-4). Several antinucleolar antibodies have recently been identified in SSc sera, and these autoantibodies were found to be correlated with specific clinical features of SSc (5-8). These findings support the concept

Address correspondence and reprint requests to Masataka Kuwana, M.D., Division of Rheumatology, Department of Internal Medicine, Keio University School of Medicine, 35 Shinanomachi, Shinjuku-ku, Tokyo 160, Japan.

Received for publication 9 October 1992.

1. Abbreviations used in this paper: Ad2, adenovirus serotype 2 late gene; EBER2, Epstein-Barr virus DNA; IPP, immunoprecipitation; pHuRI, DNA template containing human ribosomal promoter; PM, polymyositis; RNP, ribonucleoprotein; SSc, systemic sclerosis; topo I, DNA topoisomerase I; TBS, Tris-buffered saline.

J. Clin. Invest.

(c) The American Society for Clinical Investigation, Inc.

$0021-9738 / 93 / 04 / 1399 / 06 \$ 2.00$

Volume 91, April 1993, 1399-1404 that each distinctive autoantibody present in SSc serum is associated with a unique combination of clinical features. Moreover, these naturally occurring antibodies are potentially useful probes for the study of the structure and function of cellular components.

Stetler and co-workers $(9,10)$ first reported anti-RNA polymerase I antibody by radioimmunoassay using purified RNA polymerase I as the test antigen in the majority of sera from patients with SLE, mixed connective tissue disease, RA, and Sjögren's syndrome, as well as in SSc sera. Apart from those reports, Reimer et al. (11) identified an autoantibody to RNA polymerase I specifically in SSc sera because of the following evidence: $(a)$ certain SSc sera stained the same nucleolar fibrillar structures as polyclonal rabbit anti-RNA polymerase I antibody on indirect immunofluorescence; $(b)$ they immunoprecipitated 13 proteins with identical molecular weights as those precipitated by the rabbit anti-RNA polymerase I antibody; and $(c)$ microinjection of the purified IgG inhibited ribosomal RNA transcription in vivo. However, mammalian RNA polymerase $I$ is reported to be a complex enzyme that is composed of six to eight subunits $(12,13)$; therefore, the origin of the other additional immunoprecipitates produced by the antiRNA polymerase I antibody is unknown.

We describe here two types of autoantibodies reactive with all three classes of RNA polymerases, designated RNA polymerases I, II, and III, in SSc sera. This antibody is specific to SSc and identifies a subset with diffuse cutaneous SSc with serious heart and kidney involvement.

\section{Methods}

Patients and clinical features. We studied serum samples from 275 Japanese SSc patients who fulfilled the American College of Rheumatology preliminary criteria for classification as definite SSc (14). We also studied 286 additional serum samples from patients diagnosed as SLE $(n=190)$, polymyositis or dermatomyositis ( $\mathrm{PM} / \mathrm{DM} n=51)$, SLE-PM overlap $(n=10)$, and primary Raynaud's phenomenon ( $n$ $=35$ ) as control. All samples were obtained on their first visits and stored at $-20^{\circ} \mathrm{C}$ until use.

A complete history was obtained from each SSc patient, and general and scleroderma-related physical examinations were performed. Disease classification was determined as previously described (2) except for friction tendon rubs, because this sign is very rare in Japanese SSc patients. 71 patients were classified as having diffuse cutaneous SSc, 112 as having limited cutaneous SSc, and 92 as having SSc in overlap. Organ involvement was determined based on the criteria of Medsger and Masi ( 15$)$ with some modifications as follows: $(a)$ peripheral vascular system (ulcer and/or gangrene of the digits); $(b)$ joint (inflammatory arthritis); (c) esophagus, (esophagographic evidence of scleroderma-related changes in the distal esophagus); $(d)$ lung (bibasilar interstitial fibrosis observed on chest radiograph); ( $e$ ) heart (any one of the following: symptomatic pericarditis, clinical evidence of congestive heart failure, or arrhythmias requiring treatment); and $(f)$ kidney (malignant hypertension and/or rapidly progressive renal failure without any other explanation). 
Immunoprecipitation using $\left[{ }^{35}\right.$ S $]$ methionine-labeled HeLa cell extracts as a source of antigen. All experiments were performed at $4^{\circ} \mathrm{C}$ as previously described (16) with several modifications. HeLa cells (2 $\times 10^{7}$ ) were cultured in methionine-free MEM with $\left[{ }^{35} \mathrm{~S}\right]$ methionine (18.5 kBq/ml) (ICN Radiochemicals, Div. ICN Biomedicals, Inc., Irvine, CA) for $12 \mathrm{~h}$. The cells were harvested and washed with cold Tris-buffered saline ( TBS) ( $140 \mathrm{mM} \mathrm{NaCl}, 40 \mathrm{mM}$ Tris-HCl, $\mathrm{pH} 7.4)$. After being resuspended in $2 \mathrm{ml}$ of buffer containing $500 \mathrm{mM} \mathrm{NaCl}, 10$ $\mathrm{mM}$ Tris- $\mathrm{HCl}, \mathrm{pH} 8.0,0.1 \%$ Nonidet-P-40, (immunoprecipitation [IPP] buffer) supplemented with $2 \mathrm{mM}$ phenylmethylsulfonylfluoride to minimize proteolytic degradation, the cells were sonicated on ice three times for $40 \mathrm{~s}$ each and centrifuged at $14,000 \mathrm{~g}$ for $15 \mathrm{~min}$. The supernatant was used as the source of antigen.

$10 \mu \mathrm{l}$ samples of the patients' sera were incubated with $2 \mathrm{mg}$ of protein A-Sepharose CL-4B (Pharmacia, Piscataway, NJ) suspended in $500 \mu \mathrm{l}$ of IPP buffer for $12 \mathrm{~h}$. The antibody-bound beads were washed three times in IPP buffer, resuspended in $400 \mu$ l of IPP buffer, and then combined with $100 \mu \mathrm{l}$ of the $\left[{ }^{35} \mathrm{~S}\right]$ methionine-labeled HeLa cell extracts for $2 \mathrm{~h}$. After five washes with IPP buffer, the immunoprecipitated proteins were fractionated on polyacrylamide-SDS gel, enhanced with $0.5 \mathrm{M}$ sodium salicylate, and dried. The radiolabeled proteins were detected using autoradiography.

Indirect immunofluorescence. Indirect immunofluorescence was performed using commercially prepared slides of HEp-2 cells (MBL, Nagano, Japan) as a substrate. Samples were initially examined in a dilution of 1:40 in TBS, and nuclear staining was then assessed in serial dilutions. Cells were incubated with $20-\mu \mathrm{l}$ samples for $30 \mathrm{~min}$ at room temperature and then with fluorescein-conjugated goat anti-human IgG (MBL). The slides were mounted in $50 \%$ glycerol in TBS and observed with a fluorescent microscope (FX-35A; Nikon, Tokyo, Japan).

In vitro transcription assay. HeLa soluble whole-cell extract for use in the transcription assay was prepared according to the method of Manley et al. (17). To obtain a strong transcriptional activity, we added the freezing-melting step proposed by Talkington et al. (18) to the standard procedure. The transcription reaction mixture $(50 \mu \mathrm{l})$ contained $15 \mathrm{mM}$ Tris- $\mathrm{HCl}, \mathrm{pH} 7.9,7 \mathrm{mM} \mathrm{MgCl}_{2}, 32 \mathrm{mM}$ ammonium sulfate, $0.2 \mathrm{mM}$ EDTA, $1.3 \mathrm{mM}$ dithiothreitol, $10 \%$ glycerol, $600 \mu \mathrm{M}$ ATP, UTP, and CTP, $30 \mu \mathrm{M}$ GTP containing $370 \mathrm{kBq}$ of [ $\left.\alpha-{ }^{32} \mathrm{P}\right] \mathrm{GTP}$ (ICN Radiochemicals), $20 \mu \mathrm{l}$ of extract, and $1 \mu \mathrm{g}$ of DNA template. The DNA template ( $\mathrm{pHuRI}$ ) containing human ribosomal promoter (19) was kindly supplied by B. McStay and R. H. Reeder (Hutchinson Cancer Research Center, Seattle, WA). Plasmid DNA containing adenovirus serotype 2 late gene (Ad2) was used as DNA template for RNA polymerase II (20) and plasmid DNA containing Epstein-Barr virus DNA (EBER2) was used as DNA template for RNA polymerase III (21); both plasmid DNAs were kindly provided by E. Gottlieb (Yale University School of Medicine, New Haven, CT). Before use for assay, pHuRI and Ad2 were digested with BamHI and BglI, respectively. Transcription proceeded at $29^{\circ} \mathrm{C}$ for $60 \mathrm{~min}$, and RNA was extracted using phenol/chloroform/isoamylalcohol (50:50:1) and precipitated from the aqueous layer with ethanol. RNA was separated by electrophoresis on $8.3 \mathrm{M}$ urea / $5 \%$ polyacrylamide gels, and the transcribed RNAs were detected using autoradiography. For the inhibition assay, the soluble whole-cell extract was preincubated with $300 \mu \mathrm{g}$ of purified IgG or $\alpha$-amanitin (Sigma Immunochemicals, St. Louis, MO) for $30 \mathrm{~min}$ at $29^{\circ} \mathrm{C}$. Purified IgG was obtained from patients' sera using column chromatography on DEAE-cellulose (DE-52; Whatman Chemical Separation, Inc., Clifton, $\mathrm{NJ}$ ) (22).

Immunoblots. Isolated nucleoli prepared as previously described (23), and the HeLa soluble whole-cell extract were used as the antigen sources for immunoblots. An RNA polymerase-enriched fraction prepared using ion exchange chromatography $(24,25)$ was also used as the antigen source. Briefly, HeLa cell nuclei were isolated in hypertonic sucrose (26), and nuclear proteins were extracted by sonication and the following ammonium sulfate precipitation. After being dialyzed, the nuclear extract was subjected to DEAE-Sephadex A-25 column
(Whatman) and the RNA polymerase-enriched fraction was eluted with $350 \mathrm{mM}$ ammonium sulfate.

Antigen sources were fractionated on 7 or $12.5 \%$ polyacrylamideSDS gels and transferred to nitrocellulose filters (Schleicher \& Schuell, Inc., Keene, $\mathrm{NH}$ ) (27). After being blocked for $1 \mathrm{~h}$ in TBS containing $3 \%$ nonfat milk, the filters were incubated with serum samples at a dilution of 1:50 and then with ${ }^{125}$ I-labeled protein A (ICN Radiochemicals $)$ in TBS $\left(2 \times 10^{5} \mathrm{cpm} / \mathrm{ml}\right)$. Protein bands reacted by serum samples were visualized by autoradiography.

Statistical analysis. Comparisons were performed using the Fisher's exact test and the Student's $t$ test. Cumulative survival rates were calculated using life table methods, and comparisons were made using the log rank test.

\section{Results}

In screening of SSc sera by immunoprecipitation using $\left[{ }^{35} \mathrm{~S}\right]$ methionine-labeled HeLa cell extracts, we noted two types of sera that immunoprecipitated proteins with similar but not identical molecular weights to those of the immunoprecipitates produced by the anti-RNA polymerase I antibody (11). Serum from patient KA immunoprecipitated 14 proteins with molecular masses of $220 / 200,190,160,140,135$, $120,80,62,42,35,25,21,16$, and $14 \mathrm{kD}$. Another serum (patient IM) immunoprecipitated 12 proteins with the same molecular weights as those of the precipitates produced by serum KA except for the $220 / 200$ - and $140-\mathrm{kD}$ proteins (Fig. 1).

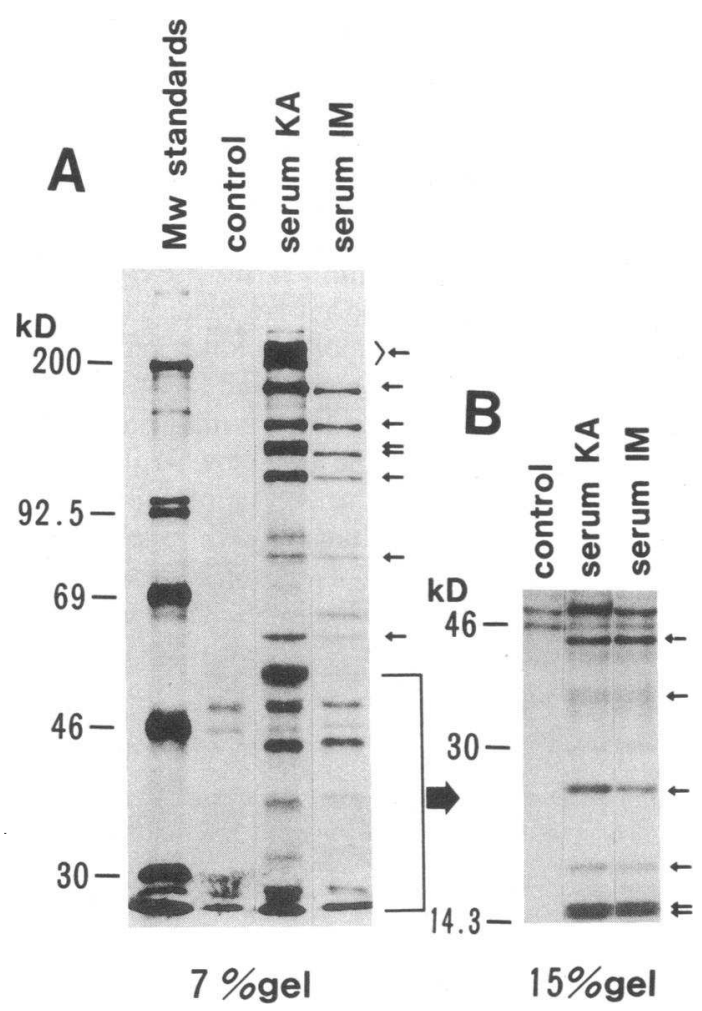

Figure 1. Autoradiograms of immunoprecipitated $\left[{ }^{35}\right.$ S $]$ methioninelabeled Hela cell proteins. The immunoprecipitated proteins were resolved in $7 \%(A)$ and $15 \%(B)$ polyacrylamide-SDS gels. Control serum precipitated nonspecific proteins. Serum KA immunoprecipitated 14 proteins with molecular masses ranging from $220 / 200$ to 14 $\mathrm{kD}$ (arrows). Serum IM immunoprecipitated 12 of the same proteins without 220/200- and 135-kD bands. The positions of molecular weight standards appear to the left of each panel. 
Eukaryotic RNA polymerases I, II, and III are composed of two large and several smaller subunits (12). Of the 12 proteins commonly immunoprecipitated by these two types of sera, the molecular masses of eight proteins $(190,120,62,42,25,21,16$, and $14 \mathrm{kD}$ ) were certainly consistent with those of eight subunits of mammalian RNA polymerase I $(12,13)$. However, three of the proteins $(160,135$, and $80 \mathrm{kD})$ had mobilities similar to those of three subunits of mammalian RNA polymerase III (12). The $220 / 200-\mathrm{kD}$ doublet protein was similar to one of the large subunits of mammalian RNA polymerases IIa and IIb, and the $140-\mathrm{kD}$ protein appeared to have the same molecular mass as the other large subunit of mammalian RNA polymerase II (12). Although the remaining $35-\mathrm{kD}$ band was weak and not singled out, all 14 sera having anti-RNA polymerase (described below) precipitated this band. Then, we believed that the $35-\mathrm{kD}$ protein is included in the roster of immunoprecipitated proteins and may correspond to hRPB 33, which has been shown to be a specific component of RNA polymerase II (28). Therefore, our findings suggested that these two types of sera immunoprecipitated the subunits of RNA polymerases II and III, as well as those of RNA polymerase I. To test this possibility, we performed the following experiments.

Indirect immunofluorescence. As shown in Fig. $2 \mathrm{~A}$, serum KA showed speckled nucleolar staining along with speckled nucleoplasmic staining. At a serum dilution of 1:1,280, the staining was limited to the nucleoli (Fig. $2 B$ ), and several bright fluorescent spots were seen in the chromosomal nucleolus organizing regions during mitosis (data not shown). In contrast, serum IM showed mainly a speckled nucleoplasmic pattern with weak nucleolar staining (Fig. $2 C$ ), but did not produce single nucleolar staining at any serum dilutions. The staining patterns confirmed that these two types of sera reacted with the nucleoplasmic component, as well as with the nucleolar structure, whereas RNA polymerase I was shown to be localized in the nucleolus $(29,30)$.
In vitro transcription inhibition assay. The purified IgG from these two types of sera were subjected to in vitro transcription inhibition assays specific to RNA polymerases I, II, and III. As shown in Fig. 3, $300 \mu \mathrm{g}$ of IgG purified from both sera completely inhibited RNA transcription catalyzed by all three classes of RNA polymerases, whereas IgG purified from anti-topo I positive SSc serum and control serum did not interfere with RNA transcription.

Taken together with the results from immunoprecipitation and indirect immunofluorescence, this observation offers convincing evidence that the two types of sera, KA and IM, reacted with all three classes of RNA polymerases.

Immunoblots. To identify the subunit of RNA polymerases recognized by these sera, we performed immunoblot analysis using three different antigen sources. Two types of sera, KA and IM, showed no significant immunoreactivity with the isolated nucleoli, even when $400 \mu \mathrm{g}$ of the substrate was loaded in each lane. When the HeLa soluble-whole cell extract was used as the antigen source, serum KA showed weak reactivity to a 25-kD protein, but serum IM showed no obvious reactivity (data not shown). Next, we used the HeLa RNA polymeraseenriched fraction in which three classes of RNA polymerases were condensed as the antigen source for immunoblotting. As shown in Fig. 4, serum KA reacted with the $25-\mathrm{kD}$ protein again and serum IM reacted with a $42-\mathrm{kD}$ protein. With prolonged exposure, serum KA also reacted with the $42-\mathrm{kD}$ protein.

Further screening for anti-RNA polymerase antibody. We examined $275 \mathrm{SSc}$ and 286 control sera for anti-RNA polymerase antibody by immunoprecipitation using ${ }^{35} \mathrm{~S}$-labeled HeLa cell extracts. The anti-RNA polymerase antibody was found in 14 SSc sera ( $5 \%$ ), but in none of the control sera from individuals with other rheumatic diseases. Serologic features of 14 SSc patients with the anti-RNA polymerase antibody are summarized in Table $\mathrm{I}$. The precipitation profile of three sera was identical to that of serum KA and the profile of the other 11
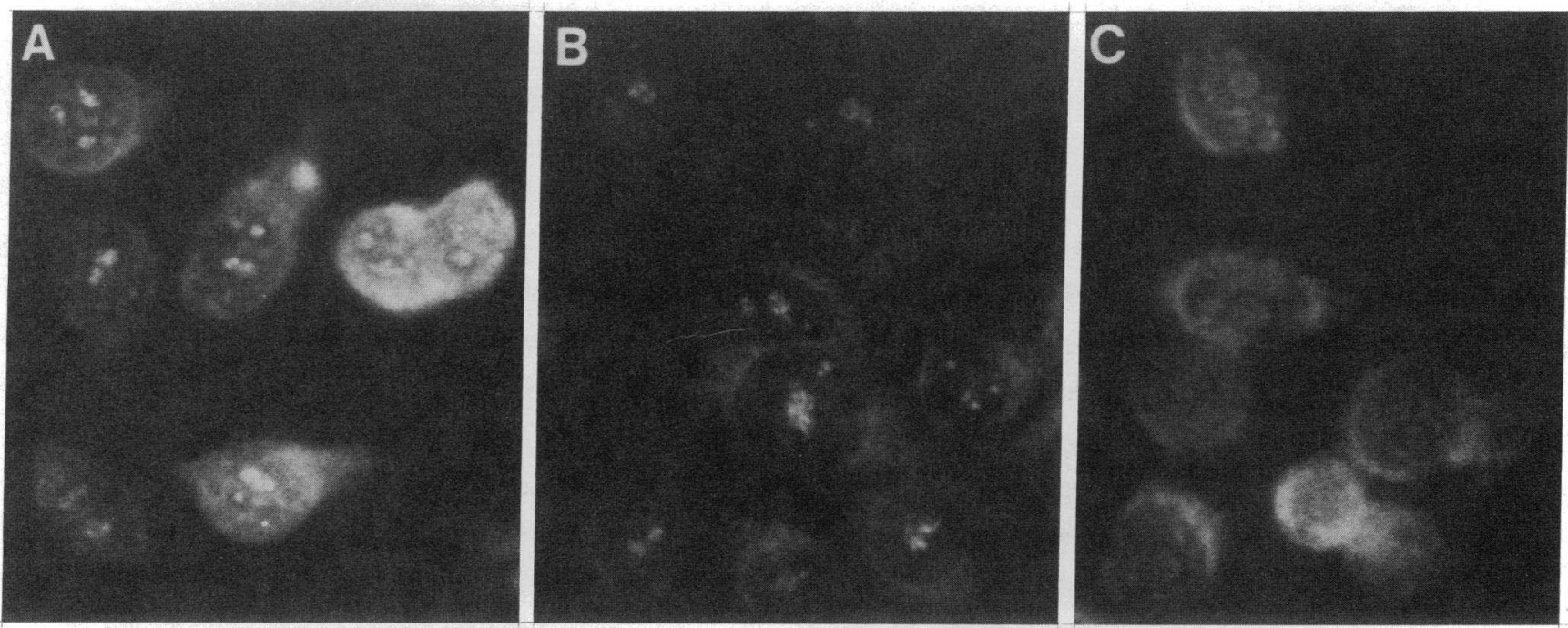

Figure 2. Indirect immunofluorescence study using HEp-2 cells as a substrate. Serum KA at a dilution of 1:160 $(A)$ and $1: 1,280(B)$ and serum IM at a serum dilution of 1:160 $(C)$ were used as the first antibody. Serum KA showed speckled nucleolar staining along with speckled nucleoplasmic staining at a dilution of 1:160, and single speckled nucleolar staining at a dilution of 1:1,280. Serum IM showed mainly a speckled nucleoplasmic pattern with weak nucleolar staining. 
A pHuRI

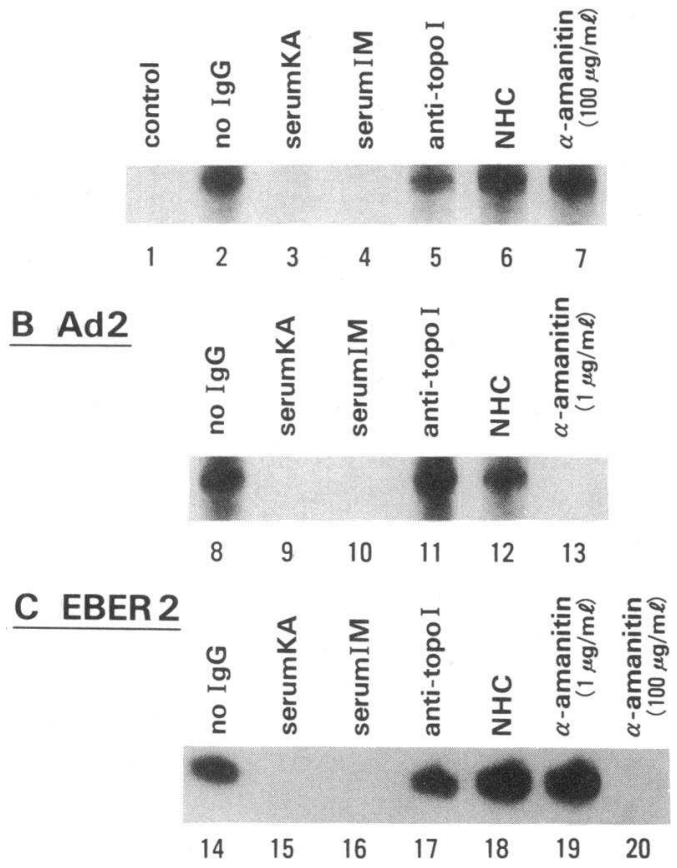

Figure 3. Effect of purified IgG from two types of sera, KA and IM, on in vitro RNA transcription assays catalyzed by RNA polymerases I, II, and III. HeLa soluble whole-cell extracts were incubated with purified IgG (300 $\mu \mathrm{g})$ and tested for their ability to transcribe DNA templates specific to RNA polymerase I ( $A$, pHuRI, except for lane $1)$, RNA polymerase II ( $B, \operatorname{Ad} 2)$, and RNA polymerase III ( $C$, EBER2). Radiolabeled transcription products were fractionated on $5 \%$ polyacrylamide gel. The DNA template used for the control (lane 1 ) was pBR322 plasmid DNA. Preincubation with IgG or $\alpha$-amanitin as follows: lanes $1,2,8$, and 14 , no IgG or $\alpha$-amanitin; lanes 3, 9, and 15 , IgG from serum $\mathrm{KA}$; lanes 4,10 , and $16, \mathrm{IgG}$ from serum $\mathrm{IM}$; lanes 5,11 , and 17 , IgG from anti-DNA topoisomerase I antibody positive SSc serum; lanes 6,12 , and 18 , IgG from normal healthy control serum; lanes 7 and $20, \alpha$-amanitin $(100 \mu \mathrm{g} / \mathrm{ml})$; lanes 13 and $19, \alpha$-amanitin $(1 \mu \mathrm{g} / \mathrm{ml})$.

sera was identical to that of serum IM. None of these 14 sera contained autoantibodies against topo I, centromere, U1 small nuclear ribonucleoprotein (RNP), U3 RNP, Th RNP, or PMScl. One serum with the 14-precipitate profile was positive for the anti-SSA/Ro antibody. Several sera immunoprecipitated additional proteins, which might be other components of the RNA polymerases or tightly bound transcription factors. It was noted that five sera with the 12-precipitate profile did not produce nucleolar staining on immunofluorescence, and four sera with this profile showed no significant reactivity on immunoblots.

Clinical features associated with anti-RNA polymerase antibody. There were no significant differences in clinical features among three patients with the 14-precipitate profile and 11 patients with the 12-precipitate profile (data not shown). Therefore, we analyzed clinical features of the anti-RNA polymerase antibody as a whole. Among 14 patients positive for the anti-RNA polymerase antibody, 13 were classified as having diffuse cutaneous SSc, and only one was classified as having limited cutaneous SSc. The frequency of this antibody in pa-



Figure 4. Immunoblot of HeLa RNA polymerase-enriched fraction. Each lane contained $400 \mu \mathrm{g}$ of the RNA polymerase-enriched fraction. The substrate was fractionated on a $12.5 \%$ polyacrylamideSDS gel. When the substrate was fractionated on a $7 \%$ gel, we did not find any high molecular weight immunoreactive protein. The positions of molecular weight standards appear to the left of the panel. $42 k$, $42 \mathrm{kD}$ protein; $25 k, 25$ $\mathrm{kD}$ protein.

tients with diffuse cutaneous SSc was significantly higher than that in patients with limited cutaneous SSc ( $18 \%$ vs $1 \%, P$ $<0.01)$. No patients demonstrated overlap features. We also compared clinical features in 13 diffuse cutaneous SSc patients positive for the anti-RNA polymerase antibody with those in 58 diffuse cutaneous SSc patients negative for this antibody. 45 patients $(78 \%)$ without the anti-RNA polymerase antibody had anti-topo I antibody. Patients with the anti-RNA polymerase antibody showed male dominance ( $62 \%$ vs $14 \%, P<0.01)$ and were older at disease onset $(52.4 \pm 12.7$ vs $43.2 \pm 13.6, P$ $<0.01$ ), compared with patients without this antibody. With regard to organ involvement (Table II), patients with the antiRNA polymerase antibody had significantly increased frequency of heart and kidney involvement, compared with patients without this antibody. In contrast, peripheral vascular and lung involvement was significantly less frequent in patients with the anti-RNA polymerase antibody.

The cumulative survival rate at $5 \mathrm{yr}$ after first visit in patients with the anti-RNA polymerase antibody was significantly lower than in those without this antibody ( $45 \%$ vs $76 \%$, $P<0.05$ ). During the follow up, six patients with this antibody died, three of myocardial failure and three of renal failure. None of patients with the anti-RNA polymerase antibody died of respiratory failure related to pulmonary interstitial fibrosis, whereas 11 of 58 patients without this antibody died of respiratory failure.

\section{Discussion}

Complex structures are common targets of autoimmunity in connective tissue diseases. For example, SLE sera often recognize the $U$ series small nuclear RNP particles $(1,31)$. We identified autoantibody reactive with all three classes of RNA polymerases in SSc sera based on the following results: $(a) 14$ of 275 SSc sera immunoprecipitated 12 or 14 proteins with similar molecular weights as those of several subunits of the mammalian RNA polymerases I, II, and III; $(b)$ by indirect immunofluorescence, all of these sera reacted with the nucleoplasmic com- 
Table I. Serologic Features of Systemic Sclerosis Patients Positive for Anti-RNA Polymerase Antibody

\begin{tabular}{|c|c|c|c|c|c|c|c|c|}
\hline & \multirow[b]{2}{*}{$\begin{array}{l}\text { Disease } \\
\text { subgroup }\end{array}$} & \multicolumn{2}{|c|}{ Immunoprecipitation } & \multicolumn{3}{|c|}{ Immunofluorescence } & \multicolumn{2}{|c|}{ Immunoblot } \\
\hline & & $\begin{array}{l}\text { Precipitate } \\
\text { profile* }^{*}\end{array}$ & $\begin{array}{c}\text { Other } \\
\text { precipitate }\end{array}$ & Titer & $\begin{array}{l}\text { Nucleolar } \\
\text { staining }\end{array}$ & $\begin{array}{l}\text { Nucleoplasmic } \\
\text { staining }\end{array}$ & $\begin{array}{l}42 \mathrm{kD} \\
\text { protein }\end{array}$ & $\begin{array}{r}25 \mathrm{kD} \\
\text { protein }\end{array}$ \\
\hline $1 .^{\ddagger}$ & Diffuse & 14 & $84 \mathrm{kD}$ & $1: 2,560$ & ++ & + & \pm & + \\
\hline 2. & Diffuse & 14 & $60 \mathrm{kD}^{8}$ & $1: 1,280$ & + & + & - & + \\
\hline 3. & Limited & 14 & - & $1: 640$ & + & + & - & + \\
\hline $4 .^{\ddagger}$ & Diffuse & 12 & $65 \mathrm{kD}$ & $1: 640$ & + & + & + & - \\
\hline 5. & Diffuse & 12 & $65 \mathrm{kD}$ & $1: 640$ & + & + & + & - \\
\hline 6. & Diffuse & 12 & $65 \mathrm{kD}$ & $1: 320$ & \pm & + & + & - \\
\hline 7. & Diffuse & 12 & 92 and $80 \mathrm{kD}$ & $1: 640$ & \pm & + & + & - \\
\hline 8. & Diffuse & 12 & - & $1: 320$ & - & + & + & - \\
\hline 9. & Diffuse & 12 & - & $1: 320$ & - & + & \pm & - \\
\hline 10. & Diffuse & 12 & - & $1: 640$ & \pm & + & \pm & - \\
\hline 11. & Diffuse & 12 & - & $1: 160$ & \pm & + & - & - \\
\hline & Diffuse & 12 & - & $1: 320$ & - & + & - & - \\
\hline 13. & Diffuse & 12 & - & $1: 160$ & - & + & - & - \\
\hline 14. & Diffuse & 12 & - & $1: 160$ & - & + & - & - \\
\hline
\end{tabular}

* 14 precipitate profile includes 14 proteins with molecular masses of $220 / 200-14 \mathrm{kD} ; 12$ precipitate profile includes the same proteins without the $220 / 200$ - and $140-\mathrm{kD}$ proteins. ${ }^{\ddagger}$ Patients 1 and 4 correspond to patient KA and IM, respectively. ${ }^{\S}$ The 60 -kD protein is a component of the SS-A/Ro particle.

ponent, and nine reacted with the nucleolar structure as well; and $(c)$ these two types of sera inhibited RNA transcription catalyzed by RNA polymerase I, II, and III in vitro. The fact that some of these sera do not react with the nucleolar structure demonstrates that indirect immunofluorescence does not always detect the anti-RNA polymerase antibody in the patients' sera.

On immunoblot, the majority of sera containing the antiRNA polymerase antibody reacted with the $42-$ or $25-\mathrm{kD}$ protein of the RNA polymerase-enriched fraction. Although the detailed structure of most subunits of three classes of RNA polymerases remain unknown in humans, it might be reasonable to conclude that the structure commonly shared by RNA polymerases I, II, and III is recognized by anti-RNA polymerase antibody in SSc sera based on the following evidence from other eukaryotes than human ones: ( $a$ ) three smaller subunits are shown to be common among all three classes of yeast RNA polymerases $(12,32-34)$; and $(b)$ immunological cross-reactiv-

Table II. Frequencies (\%) of Organ Involvement in 71 Patients with Diffuse Cutaneous Systemic Sclerosis According to the Presence or Absence of the Anti-RNA polymerase Antibody (antiRNAP)

\begin{tabular}{lccc}
\hline \multicolumn{1}{c}{ Organ involvement } & $\begin{array}{c}\text { Anti-RNAP } \\
\text { positive } \\
(n=13)\end{array}$ & $\begin{array}{c}\text { Anti-RNAP } \\
\text { negative } \\
(n=58)\end{array}$ & $P$ \\
\hline Heart & 54 & 10 & $<0.01$ \\
Kidney & 46 & 2 & $<0.01$ \\
Peripheral vascular system & 8 & 52 & $<0.01$ \\
Lung & 38 & 78 & $<0.01$ \\
Joint & 15 & 29 & NS \\
Esophagus & 67 & 75 & NS \\
& & & \\
\hline
\end{tabular}

NS, not significant. ity between RNA polymerases I and II has been also observed in rodents and the 42- and 25-kD subunits were shown to be responsible for this cross-reactivity (35-37).

Though two types of sera, KA and IM, inhibited RNA transcription of all three classes of RNA polymerases, these two sera showed several differences in their results from immunoprecipitation, indirect immunofluorescence, and immunoblot. This observation might be explained by the possibility that they recognized different autoantigenic epitope(s) on the complex structure of RNA polymerases. Further characterization of autoantigenic epitopes recognized by these sera, for example, using recombinant subunits, may clarify the detailed structure of human RNA polymerases and the autoimmune response directed against the enzymes.

The anti-RNA polymerase antibody was highly specific to SSc. However, Stetler and co-workers $(9,10)$ described that anti-RNA polymerase I antibody was detected in the majority of sera from patients with SLE, mixed connective tissue disease, RA, and Sjögren's syndrome using solid-phase radioimmunoassay. The most notable difference between our study and that of Stetler et al. is the method used for antibody detection. We used an immunoprecipitation assay using living culture cells, whereas they used biochemically purified RNA polymerase I as the antigen source for radioimmunoassay or immunoblotting. The discrepancy between the results might mean that anti-RNA polymerase I antibody in connective tissue diseases other than SSc may be directed against epitopes that are not accessible in the condition of intact complex structure of RNA polymerase I.

Clinical features associated with anti-RNA polymerases antibody are summarized as follows: $(a)$ it is specific to diffuse cutaneous SSc; $(b)$ it is frequently detected in males and aged onset patients; $(c)$ it is associated with heart and kidney involvement; $(d)$ it is negatively associated with peripheral vascular and lung involvement; and $(e)$ patients with this antibody show 
a poor survival rate at $5 \mathrm{yr}$ after their first visits. Our result confirmed the earlier reports describing the association between anti-RNA polymerase I and diffuse cutaneous SSc (6, 10). The anti-RNA polymerase antibody is common in patients with diffuse cutaneous SSc, similar to anti-topo I antibody, since this antibody was detected in $18 \%$ of patients with diffuse cutaneous SSc. It is notable that the clinical features associated with the anti-RNA polymerase antibody apparently differ from those associated with anti-topo I antibody.

In conclusion, 14 of 275 SSc sera contained autoantibody reactive with three classes of RNA polymerases. An autoimmune response to these enzymes appeared to be particularly common in patients with diffuse cutaneous SSc and a high incidence of serious heart and kidney involvement, indicating that this antibody is useful for diagnosis, disease classification, and prediction of prognosis in SSc patients.

\section{Acknowledgments}

We thank Brian McStay and Ronald H. Reeder of Hutchinson Cancer Research Center and Ellen Gottlieb of Yale University School of Medicine for generously providing the DNA templates for the RNA transcription assay. We are grateful to Takeo Sekiya of the National Cancer Center Research Institute (Tokyo, Japan) for his helpful suggestions. We also thank David B. Stollar of Tufts University School of Medicine (Medford, MA) for his careful reading of this manuscript and helpful suggestions, and Yutaka Okano of Nippon Kokan Hospital (Kawasaki, Japan) for making information available to us before publication.

This work was supported by the Scleroderma Grant for Intractable Diseases from the Japanese Ministry of Health and Welfare.

\section{References}

1. Tan, E. M. 1989. Antinuclear antibodies: diagnostic markers for autoimmune diseases and probes for cell biology. Adv. Immunol. 44:93-151.

2. Medsger, T. A., Jr. 1989. Systemic sclerosis (scleroderma), eosinophilic fasciitis, and calcinosis. In Arthritis and Allied Conditions. D. J. McCarty, editor. Lea \& Febiger, Philadelphia, PA. 1118-1165.

3. Steen, V. D., D. L. Powell, and T. A. Medsger, Jr. 1988. Clinical correlations and prognosis based on serum autoantibodies in patients with systemic sclerosis. Arthritis Rheum. 31:196-203.

4. Weiner, E. S., W. C. Earnshaw, J. L. Senècal, B. Bordwell, P. Johnson, and N. F. Rothfield. 1988. Clinical associations of anti-centromere antibodies and antibodies to topoisomerase I: a study of 355 patients. Arthritis Rheum. 31:378385.

5. Reichlin, M., P. J. Maddison, I. Targoff, T. Bunch, F. Arnett, G. Sharp, E. Treadwell, and E. M. Tan. 1984. Antibodies to a nuclear/nucleolar antigen in patients with polymyositis overlap syndrome. J. Clin. Immunol. 4:40-44.

6. Reimer, G., V. D. Steen, C. A. Penning, T. A. Medsger, Jr., and E. M. Tan. 1988. Correlates between autoantibodies to nucleolar antigens and clinical features in patients with systemic sclerosis (scleroderma). Arthritis Rheum. 31:525532.

7. Okano, Y., and T. A. Medsger, Jr. 1990. Autoantibody to Th ribonucleoprotein (nucleolar 7-2 RNA protein particle) in patients with systemic sclerosis. Arthritis Rheum. 33:1822-1828.

8. Okano, Y., V. D. Steen, and T. A. Medsger, Jr. 1992. Autoantibody to U3 nucleolar ribonucleoprotein (fibrillarin) in patients with systemic sclerosis. $A r$ thritis Rheum. 35:95-100.

9. Stetler, D. A., K. M. Rose, M. E. Wenger, C. M. Berlin, and S. T. Jacob. 1982. Antibodies to distinct polypeptides of RNA polymerase I in sera from patients with rheumatic autoimmune disease. Proc. Natl. Acad. Sci. USA. 79:7499-7503.

10. Stetler, D. A., M. Reichlin, C. M. Berlin, and S. T. Jacob. 1987. Autoantibodies against RNA polymerase I in scleroderma and Sjögren's syndrome sera. Biochem. Biophys. Res. Commun. 144:1296-1302.

11. Reimer, G., K. M. Rose, U. Scheer, and E. M. Tan. 1987. Autoantibody to RNA polymerase I in scleroderma sera. J. Clin. Invest. 79:65-72.
12. Sentenac, A. 1985. Eukaryotic RNA polymerases. CRC Crit. Rev. Biochem. 18:31-91.

13. Rose, K. M., D. A. Stetler, and S. T. Jacob. 1981. Protein kinase activity of RNA polymerase I purified from a rat hepatoma: probable function of $\mathrm{Mr}$. 42,000 and 24,600 polypeptides. Proc. Natl. Acad. Sci. USA. 78:2833-2837.

14. Subcommittee for Scleroderma Criteria of the American Rheumatism Association Diagnostic and Therapeutic Criteria Committee. 1980. Preliminary criteria for the classification of systemic sclerosis (scleroderma). Arthritis Rheum. 23:581-590.

15. Medsger, T. A., Jr., and A. T. Masi. 1972. Epidemiology of systemic sclerosis (scleroderma). Ann. Intern. Med. 74:714-721.

16. Fraccoeur, A. M., and M. B. Mathews. 1982. Interaction between VA RNA and the lupus antigen La: formation of a ribonucleoprotein particle in vitro. Proc. Natl. Acad. Sci. USA. 79:6772-6776.

17. Manley, J. L., A. Fire, A. Cano, P. A. Sharp, and M. L. Gefter. 1980. DNA-dependent transcription of adenovirus genes in a soluble whole-cell extract. Proc. Natl. Acad. Sci. USA. 77:3855-3859.

18. Talkington, C. A., Y. Nishioka, and P. Leder. 1980. In vitro transcription of normal, mutant, and truncated mouse $\alpha$-globin genes. Proc. Natl. Acad. Sci. USA. 77:7132-7136.

19. Learned, R. M., and R. Tjian. 1981. In vitro transcription of human ribosomal RNA genes by RNA polymerase I. J. Mol. Appl. Genet. 1:575-584.

20. Weil, P. A., D. S. Luse, J. Segall, and R. G. Roeder. 1979. Selective and accurate initiation of transcription at the $\mathrm{Ad}_{2}$ major late promoter in a soluble system dependent on purified RNA polymerase II and DNA. Cell. 18:469-484.

21. Gottlieb, E., and J. A. Steitz. 1989. The RNA binding protein La influences both the accuracy and the efficiency of RNA polymerase III transcription in vitro. EMBO (Eur. Mol. Biol. Organ.) J. 8:841-850.

22. Gravey, J. S., N. E. Cremer, and D. H. Sussdorf. 1977. Methods in Immunology. W. A. Benjamin, Reading, MA. 215 pp.

23. Reimer, G., K. M. Pollard, C. A. Penning, R. L. Ochs, M. A. Lischwe, H. Busch, and E. M. Tan. 1987. Monoclonal autoantibody from a (New Zealand black $\times$ New Zealand white) F1 mouse and some human scleroderma sera target an $\mathrm{Mr} 34,000$ nucleolar protein on the U3 RNP particle. Arthritis Rheum. 30:793-800.

24. Rose, K. M., P. A. Ruch, H. P. Morris, and S. T. Jacob. 1976. RNA polymerases from rat hepatoma: partial purification and comparison of properties with corresponding liver enzymes. Biochim. Biophys. Acta. 432:60-72.

25. Sugden, B., and W. Keller. 1973. Mammalian deoxyribonucleic acid-dependent ribonucleic acid polymerases. I. Purification and properties of an $\alpha$ amanitin-sensitive ribonucleic acid polymerase and stimulatory factors from HeLa and KB cells. J. Biol. Chem. 248:3777-3788.

26. Evans, J., A. Reuben, and J. Craft. 1991. PBC 95K, a 95-kilodalton nuclear autoantigen in primary biliary cirrhosis. Arthritis Rheum. 34:731-736.

27. Towbin, H., T. Staehelin, and J. Gordon. 1979. Electrophoretic transfer from polyacrylamide gels to nitrocellulose sheets: procedure and some applications. Proc. Natl. Acad. Sci. USA. 76:4350-4354.

28. Pati, U. K., and S. M. Weissman. 1990. The amino acid sequence of the human RNA polymerase II 33-kDa subunit hRPB33 is highly conserved among eukaryotes. J. Biol. Chem. 265:8400-8403.

29. Rose, K. M., D. A. Stetler, and S. T. Jacob. 1983. RNA polymerases from higher eukaryotes. In Enzymes of Nucleic Acid Synthesis and Modification. Vol. II. RNA Enzymes. S. T. Jacob, editor. CRC Press, Inc., Boca Raton, FL. 43-74.

30. Scheer, U., B. Hugle, R. Hazan, and K. M. Rose. 1984. Drug-induced dispersal of transcribed rRNA genes and transcriptional products: immunolocalization and silver staining of different nucleolar components in rat cells treated with 5,6-dichloro- $\beta$-D-ribofuranosylbenzimidazole. J. Cell Biol. 99:672-679.

31. Lerner, M. R., and J. A. Steitz. 1979. Antibodies to small nuclear RNAs complexed with proteins are produced by patients with systemic lupus erythematosus. Proc. Natl. Acad. Sci. USA. 76:5495-5499.

32. Buhler, J. M., F. Iborra, A. Sentenac, and P. Fromageot. 1976. Structure studies in yeast RNA polymerases: existence of common subunits in RNA polymerases A(I) and B(II). J. Biol. Chem. 251:1712-1717.

33. Buhler, J. M., J. Huet, K. E. Davies, A. Sentenac, and P. Fromageot. 1980. Immunological studies of yeast nuclear RNA polymerases at the subunit level. $J$. Biol. Chem. 255:9949-9954.

34. Woychik, N. A., S. M. Liao, P. A. Kolodziej, and R. A. Young. 1990. Subunits shared by eukaryotic nuclear RNA polymerases. Genes \& Dev. 4:313323.

35. Ingles, C. J. 1973. Antigenic homology of eukaryotic RNA polymerases. Biochem. Biophys. Res. Commun. 55:364-371.

36. Kedinger, C., F. Gissenger, and P. Chambon. 1974. Animal DNA-dependent RNA polymerases: Molecular structures and immunological properties of calf-thymus enzyme AI and of calf-thymus and rat-liver enzyme B. Eur. J. Biochem. 44:421-436.

37. Stetler, D. A., and M. Rose. 1983. Protein kinase NII: interaction with RNA polymerase II and contribution to immunological cross-reactivity of RNA polymerase I and II. Biochim. Biophys. Acta. 739:105-113. 